\title{
Comparative analysis of optimization algorithms for converted wave (PS) events
}

\section{Nelson Ricardo Coelho Flores Zuniga (IAG-USP)}

Copyright 2021, SBGf - Sociedade Brasileira de Geofísica

This paper was prepared for presentation during the $17^{\text {th }}$ International Congress of the Brazilian Geophysical Society held in Rio de Janeiro, Brazil, 16-19 August 2021.

Contents of this paper were reviewed by the Technical Committee of the $17^{\text {th }}$ International Congress of the Brazilian Geophysical Society and do not necessarily represent any position of the SBGf, its officers or members. Electronic reproduction or storage of any part of this paper for commercial purposes without the written consent of the Brazilian Geophysical Society is prohibited.

\section{Abstract}

Latterly, to determine the RMS velocity of a nonhyperbolic event of the top of an ultra-deep reservoir is a very common challenge for the offshore exploration, which demands a more complex seismic processing. For this reason, an inversion procedure, under an optimization criterion, was performed to calculate the RMS velocity of the reflected PS event, with eight different travel-time approximations and five different optimization algorithms. Each approximation with each algorithm were compared, and the errors between the observed seismic event and the calculated one were computed. Then, it was possible to determine the best combination of nonhyperbolic approximation and optimization algorithm, for this kind of converted PS event.

\section{Introduction}

Previous works showed how complex is to perform an inversion procedure aiming to recover information concerning the velocity analysis for a reflected conventional (PP) or converted (PS) event (Aleixo and Schleicher, 2010; Golikov and Stovas, 2012; Zuniga 2017 and 2021). For this reason, not only different nonhyperbolic multiparametric travel-time approximations must be tested in order to find out which one produces the lowest error; the selection of the most appropriate optimization algorithm is almost equally important, which makes necessary to compare each nonhyperbolic approximation among each other, and with each selected optimization algorithm.

Seven equations, exhaustively tested in previous works (Aleixo and Schleicher, 2010; Golikov and Stovas, 2012; Zuniga 2017), were used and compared to a recently proposed approximation (Zuniga, 2021) —each one tested with five different optimization algorithms - aiming to find out which one is able to recover the velocity of the reflected event with the lowest error; and therefore, to find out which one provides the most appropriate RMS velocity.

\section{Model}

The model used in this work is from Pre-salt data analyzed from Santos Basin (Figure 1), and the reservoirs are at more than 5000 meters depth, and the water depth is more than 2000 meters depth.
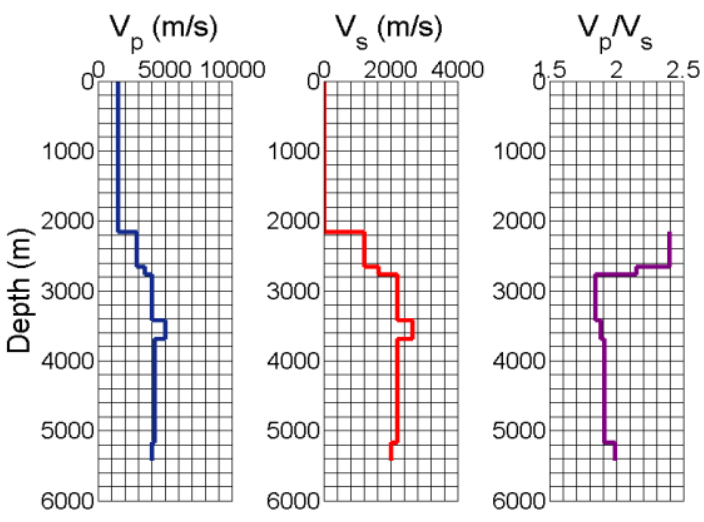

Figure 1: P-wave velocity (Vp), S-wave velocity $(\mathrm{Vs})$ and $\mathrm{Vp} / \mathrm{Vs}$ ratio for the Pre-salt model from Santos Basin.

\section{Method}

Several comparisons were performed considering different nonhyperbolic travel-time approximations (Zuniga, 2017); however, only recently (Zuniga, 2021), different optimization algorithms were tested to perform the inversion for different nonhyperbolic approximations.

The approximations tested in this work were previously studied also by different authors (e.g. Thomsen, 1986; Castle, 1988 and 1994; Tsvankin and Thomsen, 1994; Li and Yuan, 1999; Tsvankin and Grechka, 2000a and 2000b; Fomel and Grechka, 2000 and 2001; Tsvankin, 2001; Yuan and Li, 2002; Li, 2003).

For a comparison effect the hyperbola equation was used.

Equation 1 - Dix (1955), the hyperbola equation.

$$
t=\sqrt{t_{0}^{2}+\frac{x^{2}}{v^{2}}}
$$

The nonhypeebolic multiparametric travel-time approximations used were:

Equation 2 - Malovichko (1978). 


$$
t=t_{0}^{2}\left(1-\frac{1}{s}\right)+\frac{1}{s} \sqrt{t_{0}^{2}+\frac{s x^{2}}{v^{2}}}
$$

Equation 3 - Alkhalifah and Tsvankin (1995).

$$
t=\sqrt{t_{0}^{2}+\frac{x^{2}}{v^{2}}-\frac{2 \eta x^{4}}{v^{2}\left[t_{0}^{2} v^{2}+(1+2 \eta) x^{2}\right]}}
$$

Equation 4 - Ursin and Stovas (2006).

$$
t=\sqrt{t_{0}^{2}+\frac{x^{2}}{v^{2}}-\frac{(s-1) x^{4}}{4 v^{4}\left(t_{0}^{2}+\frac{(S-1)}{2} \frac{x^{2}}{v^{2}}\right)}}
$$

Equation 5 (Blias, 2009).

$t=\frac{1}{2} \sqrt{t_{0}^{2}+\frac{1-\sqrt{S-1}}{v^{2}}} x^{2}+\frac{1}{2} \sqrt{t_{0}^{2}+\frac{1+\sqrt{S-1}}{v^{2}}} x^{2}$

Equation 6 - Muir and Dellinger (1985).

$$
t=\sqrt{t_{0}^{2}+\frac{x^{2}}{v^{2}}-\frac{f(1-f) x^{4}}{v^{2}\left(v^{2} t_{0}^{2}+f x^{2}\right)}}
$$

Equation $7-\mathrm{Li}$ and Yuan (2001).

$$
t=\sqrt{t_{0}^{2}+\frac{x^{2}}{v^{2}}-\frac{(\gamma-1)}{\gamma v^{2}} \frac{(\gamma-1) x^{4}}{4 t_{0}^{2} v^{2}+(\gamma-1) x^{2}}}
$$

Equation 8 - Zuniga (2021), the most recently approximation developed, which is proposed to be tested for several optimization algorithms.

$$
t=\sqrt{t_{0}^{2}+\frac{x^{2}}{V^{2}}+\frac{-(\gamma-1)^{2} x^{4}\left(1+\frac{z_{W D} V_{W D}}{t_{0} V^{2}}\right)^{4}}{\gamma V^{2}\left[4 t_{0}^{2} V^{2}+(1-\gamma) x^{2}\left(1+\frac{z_{W D} V_{W D}}{t_{0} V^{2}}\right)^{2}\right]}}
$$

Where, for the approximations used in this work, $t$ is the travel-time, $x$ is the offsets, $t_{0}$ is the time for zero-offset and $v$ is the velocity of reflected wave. The $\mathrm{S}$ parameter is the heterogeneity parameter. The $\eta$ parameter is the one which quantifies the nonhyperbolicity concerning the anisotropy. The $f$ parameter is the anellipitical parameter. The $\gamma$ parameter considers the effects of wave conversion, anisotropy and heterogeneity. For Eq. 8, the $Z W D$ and $V_{W D}$, are a priori parameters, which are, respectively, the water depth and the velocity of the Pwave traveling through the water.

The four optimization algorithms used here with the multistart procedure were:

FMINSEARCH (Find Minimum Search) is a MATLAB implementation of the Nelder-Mead algorithm (Nelder and Mead, 1965). This local search algorithm is focused in the use of a simplex, a polytope of $n+1$ vertices in $n$ dimensions with edges of the same size, and it is useful for unconstrained optimization problems.

SID-PSM (Simplex Derivative - Pattern Search Method) is a local search algorithm implemented in MATLAB, based on a pattern search method with the pool step guided by simplex derivatives. This kind of algorithm was created to solve unconstrained and constrained problems, and each search step is based on the optimization of quadratic surrogate models (Custódio et al., 2010).

MCS (Multilevel Coordinate Search) is a MATLAB implementation of the algorithm for global optimization of bound-constrained problems (Neumaier et al., 2005). This algorithm is based on performing the partition of the search space into boxes with an evaluated base point.

The TOMLAB/LGO is a TOMLAB solver implemented in MATLAB. This kind of solver provides access to several derivative-free optimization solvers (Holmström et al., 2008). The LGO (Local and Global Optimization) solver used is a combination of global and local nonlinear solvers that implements a combination of Lipschitzianbased branch-and-bound with deterministic and stochastic local search.

It was computed the differences between the observed and the calculated curve as a percentual travel-time error, information which allow us to compare the accuracy among each approximation with each optimization algorithm.

\section{Results}

In a general manner, the hyperbola equation (Dix, 1955) showed the worst results, as it was expected, due to the complexity of the reflection events.

Figure 1 shows that the Equation 8 is more accurate for the first algorithm used.

Equation 7 showed very good results very similarly to Equation 8, while Equation 5 is just a little less accurate than the other two nonhyperbolic approximations.

Equations 2 and 6 showed less accurate results, even though their quality of the accuracy still being high. Equations 3 and 4 showed a higher error than the other approximation.

In Figure 2, it is possible to observe that the SID-PSM optimization algorithm showed a strong enhancement concerning the quality of the accuracy; while, in Figure 3, MCS algorithm showed another significant increase concerning the accuracy.

Figure 4 showed that for all approximations, none of them showed a significant increase concerning the accuracy when the TOMLAB/LGO optimization algorithm was used in comparison to MCS algorithm. 


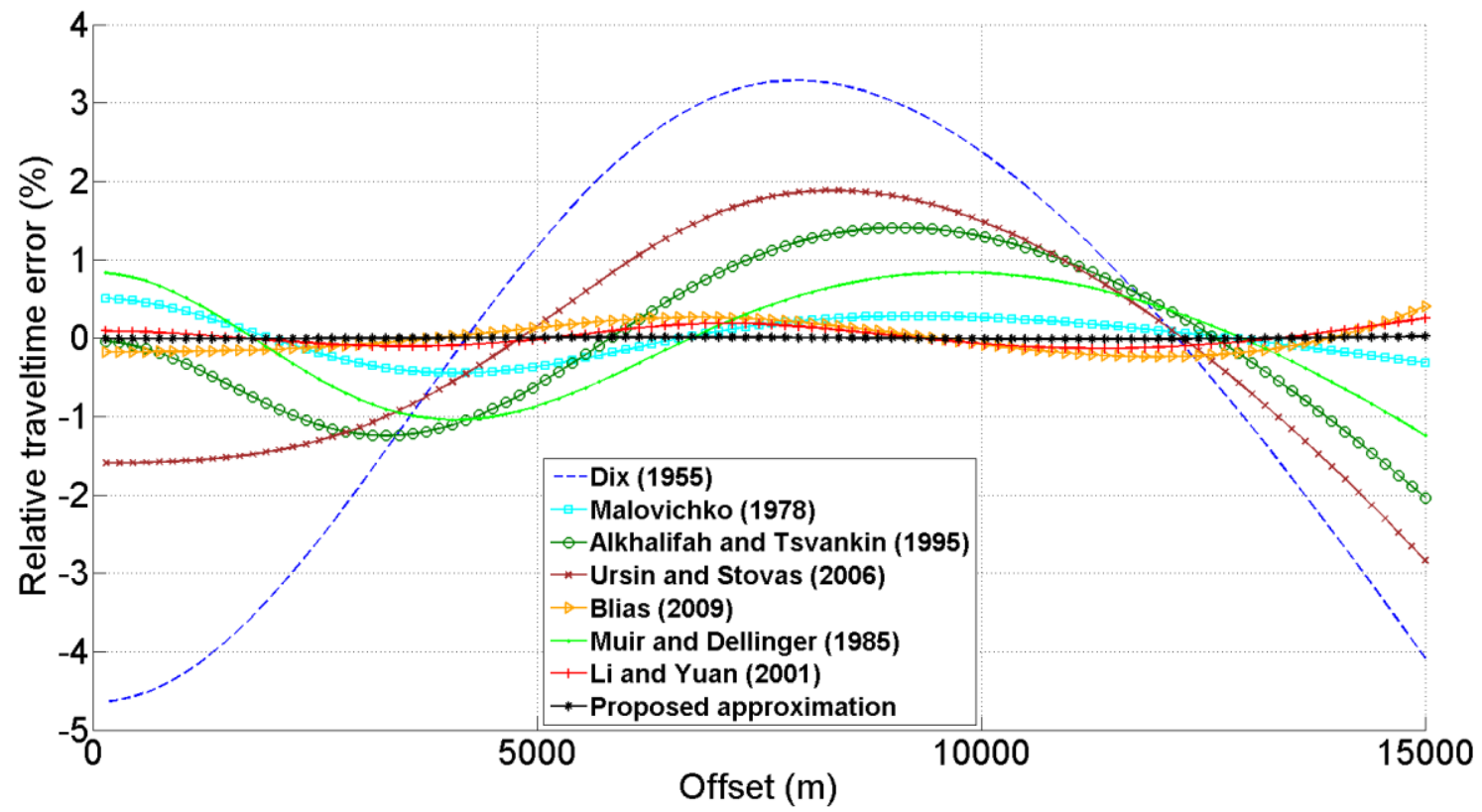

Figure 2: Relative error in travel-time between the observed curve and the calculated curve with each approximation of the PS reflection event with FMINSEARCH optimization algorithm.

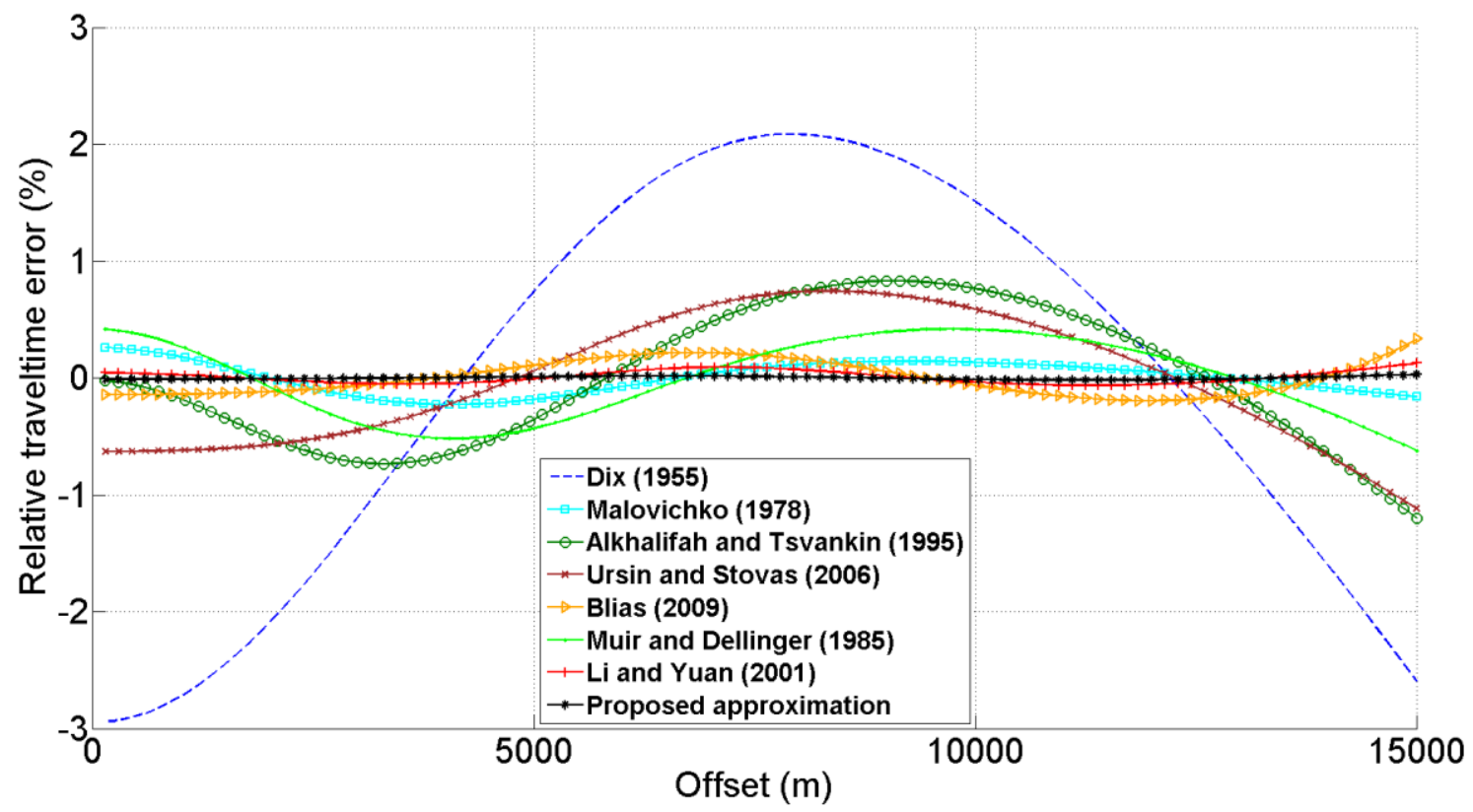

Figure 4: Relative error in travel-time between the observed curve and the calculated curve with each approximation of the PS reflection event with SID-PSM optimization algorithm. 


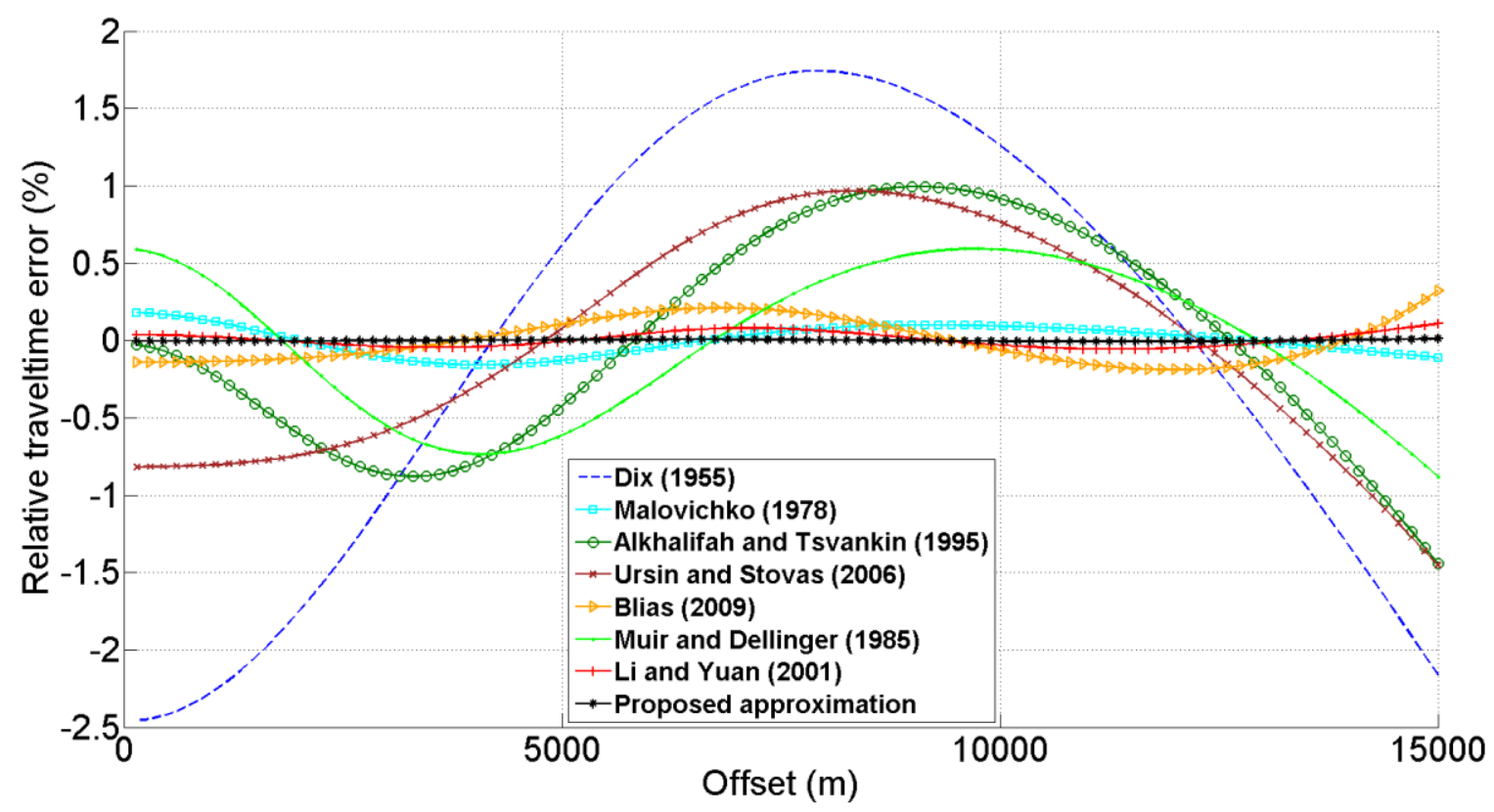

Figure 5: Relative error in travel-time between the observed curve and the calculated curve with each approximation of the PS reflection event with MCS optimization algorithm.

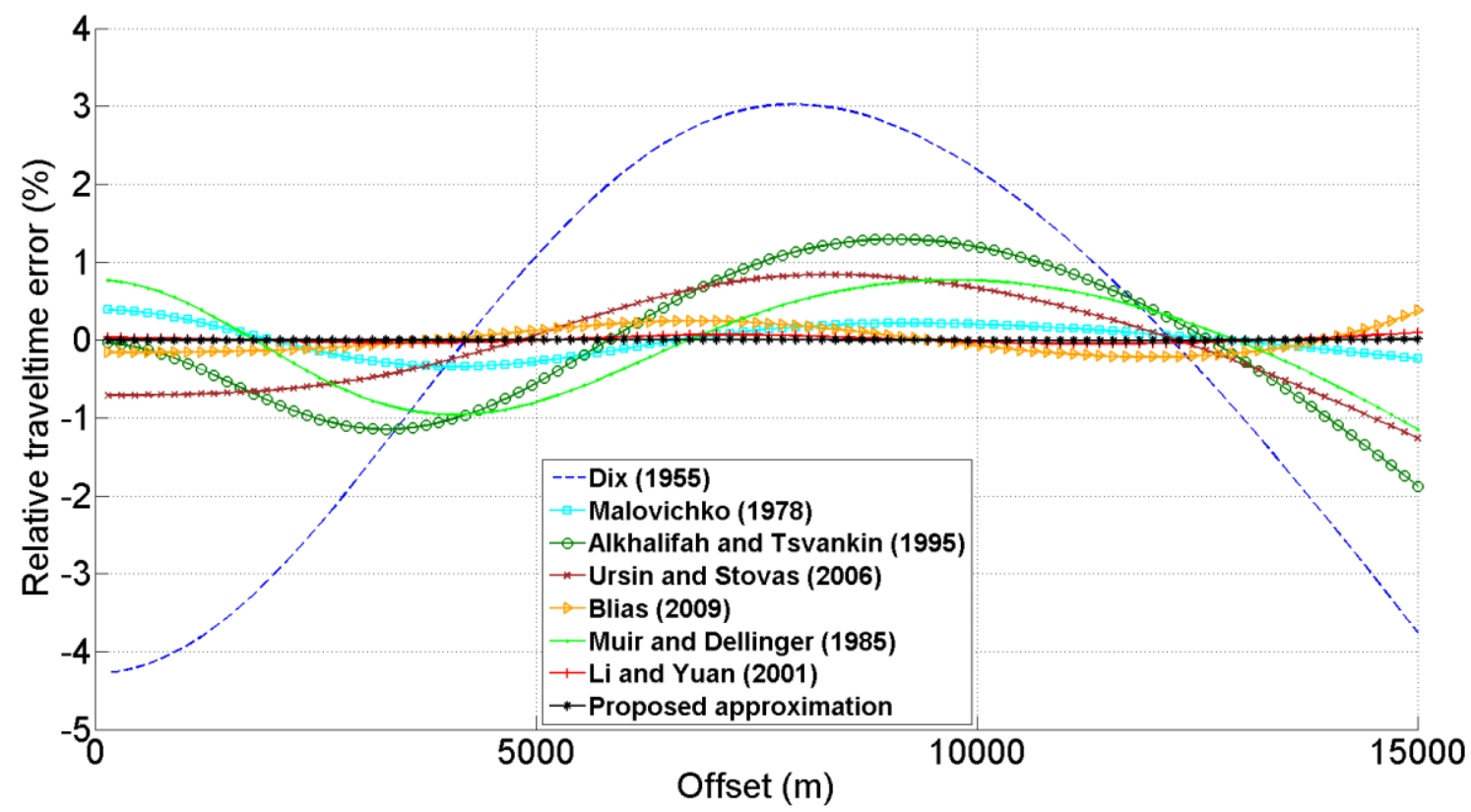

Figure 5: Relative error in travel-time between the observed curve and the calculated curve with each approximation of the PS reflection event with TOMLAB/LGO optimization algorithm. 


\section{Conclusions}

Considering the results found by Zuniga (2021), the FMINSEARCH optimization algorithm presented to be $68 \%$ mor accurate, the SID-PSM algorithm showed a mean increase of $78 \%$, the MCS algorithm presented to be $83 \%$ more accurate, and TOMLAB/LGO optimization algorithm showed to be the most accurate with $85 \%$ of increase concerning the accuracy. However, the processing time of the TOMLAB/LGO algorithm is almost twice higher than the MCS (Zuniga, 2021), which makes the MCS algorithm, the best option for this kind of problem, even though being $2 \%$ less accurate.

The Equation 8 (Zuniga, 2021) presented the best results for all optimization algorithms for this kind of reservoir. However, more tests must be performed for different structures, since this approximation is very recent and it has not been tested for a significant diversity of models.

\section{References}

ALEIXO, R.; SCHLEICHER, J. Traveltime approximations for $\mathrm{q}-\mathrm{P}$ waves in vertical transversely isotropic media.

Geophys. Prospect.Vol. 58, p. 191-201, 2010.

ALKHALIFAH, T.; TSVANKIN, I. Velocity analysis for transversely isotropic Media. Geophysics, v. 60, p. 1550-1566, 1995.

BLIAS, E. Long-offset NMO approximations for a layered VTI model: Model study. In: 79th Annual International Meeting: Society of Exploration Geophysics, 2009. Expanded Abstract..., 2009.

CASTLE, R. A theory of normal moveout. Geophysics, v. 59, p. 983-999, 1994.

CASTLE, R.J. Shifted hyperbolas and normal moveout. In: 58 th Annual International Meeting: Society of Exploration Geophysics, 1988. Expanded Abstracts..., p. 894-896. 1988.

CUSTÓDIO, A. L; ROCHA, H; VICENTE, L. N. Incorporating minimum Frobenius norm models in direct search. Computational Optimizing and Applications, 46, 265-278, 2010

DIX, C. H. Seismic velocities from surface measurements: Geophysics, 20, p.68-86, 1955.

FOMEL, S.; GRECHKA, V. On nonhyperbolic reflection moveout in anisotropic media. Standford Exploration Project, p.617-640, 2000.

FOMEL, S.; GRECHKA, V. Nonhyperbolic reflection moveout of $P$ waves. An overview and comparison of reason: Colorado School of Report CWP-372, 2001.

GOLIKOV, P.; STOVAS, A. Accuracy comparison of nonhyperbolic moveout approximations for $\mathrm{qP}$-waves in VTI media. Journal of Geophysics and Engineering. Vol. 9, 428-432, 2012.

HOLMSTRÖM, K; QUTTINEH, N. H; EDVALL, M. M. An adaptive radial basis algorithm (ARBF) for expensive black-box mixed-integer constrained global optimization. Optimization and Engineering, 9, 311-339, 2008.

LI, X. Y.; YUAN, J. Converted-waves moveout and parameter estimation for transverse isotropy. 61st EAGE Conference, Expanded Abstract, v. 1, p. 4-35, 1999.

LI, X.Y.; YUAN, J. Converted wave imaging in inhomogeneous, anisotropic media: Part I. Parameter estimation. In: 63rdEAGE conference, Expanded Abstract, v. 1, p. 109, 2001.

LI, X. Y.; Converted-wave moveout analysis revisited: The search for a standard approach, 73rd Annual internat. Mtg. Soc. Expl. Geophysics, Expanded Abstract, p. 805-808, 2003.

MALOVICHKO, A. A. A new representation of the traveltime curve of reflected waves in horizontally layered media. Applied Geophysics (in Russian), v. 91, n. 1, p. 47-53, 1978.

MUIR, F.; DELLINGER, J. A practical anisotropic system, in SEP-44. Stanford Exploration Project, p. 55-58, 1985.

NELDER, J. A; MEAD, R. A simplex method for function minimization. The Computer Journal, 7, 308-313, 1965.

NEUMAIER, A; SHCHERBINA, R; HUYER, W; VINKÓ, T. A comparison of complete global optimization solvers. Mathematical Programming, 103, 335-356, 2005.

TSVANKIN, I. Seismic Signatures and analysis of reaction data in anisotropic media. Elsevier, 2001.

TSVANKIN, I.; GRECHKA, V. Dip moveout of converted waves and parameter estimation in transversely isotropic media. Geophysics, v. 48, p. 257-292, 2000a.

TSVANKIN, I.; GRECHKA, V. Two approaches to anisotropic velocity analysis of converted waves. In: 70th Annual Internat. Mtg., Soc. Expl. Expanded Abstrdact, p. 1193-1196, 2000b.

TSVANKIN, I.; THOMSEN, L. Nonhyperbolic reflection moveout in anisotropic media. Geophysics, v. 59, p. 1290-1304, 1994.

URSIN, B.; STOVAS, A. Traveltime approximations for a layered transversely isotropic medium. Geophysics, v. 71, p. 23-33, 2006.

ZUNIGA, N. R. C. F. Análise comparativa de aproximações não-hiperbólicas dos tempos de trânsito de dados sísmicos multicomponente utilizando tecnologia OBN. Master's Thesis, Universidade de São Paulo, São Paulo, 2017.

ZUNIGA, N. R. C. F. Nonhyperbolic multiparametric travel-time approximation for converted-wave and OBN data. PhD Thesis, Universidade de São Paulo, São Paulo, 2021. 